\title{
Evaluation of Gaps or Voids Occurring in Roots Filled with Three Different Sealers
}

\author{
Melek Akmana \\ Serhan Akman ${ }^{b}$ \\ Oznur Derinbaya \\ Sema Bellic
}

\section{ABSTRACT}

Objectives: The purpose of this in vitro study was to evaluate gaps or voids occurring in roots filled with three different sealers.

Methods: Thirty extracted human single-rooted teeth were decoronated, instrumented using NiTi rotary instruments, divided into three groups ( $n=10$ per group) and obturated with one of the following: Epiphany with Resilon, MetaSEAL with gutta-percha or AH Plus with gutta-percha using the match-taper single-cone technique. After storage for one week in $100 \%$ humidity at $37^{\circ} \mathrm{C}$, the teeth were horizontally sectioned $(n=10)$. Photographs were taken from the coronal, median and apical parts of the roots using a stereomicroscope at 10X magnification, and the images were then transferred to a computer. The mathematical method known as the 'Affine Transformation' was used for the transformation of pixel coordinates to ground coordinates in the Netcad Software program. The mean areas $\left(\mu \mathrm{m}^{2}\right)$ of the gaps between the sealer and root dentin or gutta percha/resilon and the gaps between the sealer and/or voids inside the sealer mass were measured, scored on a 0-3 scale and statistically analyzed with the Kruskal-Wallis test.

Results: The mean total area of gaps or voids for each sealer was $4631.80 \mu \mathrm{m}^{2}$ for the EpiphanyResilon, $3826.80 \mu \mathrm{m}^{2}$ for the MetaSEAL-gutta-percha and $31334 \mu \mathrm{m}^{2}$ for the AH Plus-gutta-percha. The MetaSEAL-gutta-percha group showed more gap or void-free interfaces. No significant differences were found among the sealers in the scores for the gap areas $(P<.05)$, and the MetaSEAL showed similar interfaces with Epiphany.

Conclusions: No significant differences in the mean areas of gaps or voids were found among the tested resin-based sealers. (Eur J Dent 2010;4:101-109)

Key words: Gap; Void; Sealer; Affine transformation; Endodontic treatment.

a Research Assistant, Department of Endodontics, Faculty of Dentistry, University of Selcuk, Konya, Turkey.

b Assistant Professor, Department of Prosthodontics, Faculty of Dentistry, University of Selcuk, Konya, Turkey.

Professor and Chair, Department of Endodontics, Faculty of Dentistry, University of Selcuk, Konya, Turkey.

- Corresponding author: Serhan Akman, University of Selcuk, Faculty of Dentistry, Department of Prosthodontics, 42079, Campus, Konya, Turkey.

Phone: +90 3322231162 Fax: + 903322410062

E-mail: serhanakmandaselcuk.edu.tr

\section{INTRODUCTION}

The goal of an endodontic treatment is to eliminate microbial challenges from the root canal system and to develop a complete seal using a stable and biocompatible material. ${ }^{1}$ Improvements in adhesive technology have focused research efforts on bonding to root canal walls, and resin-bonded root-canal sealers were then suggested for use. ${ }^{2-5}$ The Resilon/Epiphany system (Pentron Clinical Technologies, LLC, Wallingford, CT, US $)^{3}$ is one of these sealers and was introduced as a promising root canal obturation ma- 
terial. Resilon (Resilon Research, LLC, Madison, CT, US) is a synthetic polymer-based material and contains bioactive glass and radiopaque fillers. ${ }^{6}$ The Resilon/Epiphany (Pentron Clinical Technologies, Wallingford, CT, US) combination forms a monoblock within the root canal. ${ }^{7}$ Furthermore, the dual-cure characteristic gives the system an advantage. ${ }^{8}$

Dentine-bonding agents may have the potential to enhance the root canal seal. Conventional or multi-step bonding systems could have an incomplete infiltration of the demineralized dentine, resulting in unprotected collagen and hydroxyapatite crystals that are vulnerable to degradation. Self-etch adhesive systems were developed as an alternative. In self-etch systems, the acidic part of the primer dissolves the smear layer, incorporating it into the mixture as it demineralizes the dentine and encapsulates the collagen fibers and hydroxyapatite crystals. ${ }^{9,10}$

Recently, a 4-methacryloyloxyethyl trimellitate anhydride (4-META) containing polymethyl mathacrylate based (PMMA) dual-curable and self-etching resin cement has been introduced for endodontic use (MetaSEAL; Parkell Inc., Farmington, NY, USA). Methacrylates with hydrophobic and hydrophilic groups such as 4-META promote monomer diffusion into the acid-conditioned and underlying intact dentine, and their polymerization produces functional hybridized dentin. ${ }^{11,12}$ The formation of hybridized dentin is the major mechanism of bonding and a high quality hybridized dentine ${ }^{13}$ resists acid challenge. ${ }^{12} \mathrm{~A}$ minimal hybrid layer was seen in radicular dentin with MetaSEAL, and the lower dislocation resistance in MetaSEAL filled canals challenges the use of a self-adhesive bonding mechanism to create continuous bonds inside the root canals. ${ }^{14}$

Several studies were done to evaluate sealers in terms of their susceptibility to degradation, ${ }^{15}$ cytotoxicity, ${ }^{16}$ bondability, ${ }^{17,18}$ sealing ability ${ }^{19,20}$ and biocompatibility. ${ }^{21}$ Mutal and Gani reported that there were few reports available on the presence of voids within the sealer mass. ${ }^{22}$ Studies were later done to evaluate the gaps or voids within the sealer either using stereomicroscopes, digital images and computer program ${ }^{23-26}$ or using microCT. ${ }^{27}$

For evaluating the gaps or voids on digital images, calculations are necessary. The most com- mon method of transformation from the machine coordinate system into the true image coordinate system is the 'Affine Transformation' method. The Affine Transformation is generally used in engineering and photogrammetric fields. The method basically depends on the transformation of pixel coordinates to ground coordinates, which is expressed by the following equation: ${ }^{28}$

$$
\left(\begin{array}{l}
\xi \\
\eta
\end{array}\right)=\left(\begin{array}{l}
a_{01} \\
a_{02}
\end{array}\right)+\left(\begin{array}{ll}
a_{11} & a_{21} \\
a_{12} & a_{22}
\end{array}\right)\left(\begin{array}{l}
\xi^{\prime} \\
\eta^{\prime}
\end{array}\right)
$$

$a_{01}, a_{02}, a_{11}, a_{21} a_{12}, a_{22}$ : affine transformation parameters; $\xi^{\prime}, \eta$ ! pixel coordinates; $\xi^{\prime}, \eta$ : ground control point coordinates.

The aim of this study was to quantitatively evaluate the gaps (between the sealer and root dentin or gutta percha/resilon and sealer) or voids (within the sealer mass) in roots filled with three different sealers, using a computer program that makes affine transformation calculations (NetCad, Ak Mühendislik Ltd. Sti. Ankara, Turkeyl and to evaluate whether the distribution of the gaps or voids inside the root canal system differ according to the sealer or region.

\section{MATERIALS AND METHODS}

Extracted human teeth with straight roots and fully formed apices were selected for this study. The teeth were scaled with a periodontal scaler to remove soft tissue and calculus; radiographs were taken to confirm the presence of a single canal and then decoronated at the cemento-enamel junction to leave a root length of $11 \mathrm{~mm}$ using a diamond bur (Dia Burs, Mani Inc., Utsunomiya, Tochigi, Japan) under cooling. Thirty-three teeth with round canals were selected, and the patency of the root canals was verified with a \#15 Kfile (Dentsply Maillefer, Tulsa, OK). The working length was determined by inserting the file into the canal until it was just visible at the apical foramen, then subtracting $1 \mathrm{~mm}$ from the measured length. The canals were then instrumented using the crown-down technique with ProFile 0.04 tapered NiTi rotary instruments (Dentsply, Tulsa Dental, Tulsa, OKJ until a \#45 file fit at working length. For irrigation solution, $2.5 \mathrm{ml}$ of $5 \% \mathrm{NaOCl}$, was used, and the final rinse was done with $3 \mathrm{ml}$ of $17 \%$ EDTA followed by $3 \mathrm{ml}$ of distilled water. The canals were dried with paper points (Gapadent Co. Ltd. Xinkou Town, Tianjin, China), randomly 
divided into 3 groups ( $n=11)$ and obturated using a single-cone technique with one of the sealers given in Table 1. Details are as follows:

Group 1: The Epiphany primer was introduced into the canal with a paper point, and the Epiphany sealer was applied to the canal with a lentulo spiral filler (Dentsply, Maillefer, Switzerland). A size 45, .04 tapered Resilon point was coated with Epiphany sealer and fitted to working length with tug-back. The excess material was cleaned, and the roots were light-cured from the coronal side for $40 \mathrm{~s}$ using a halogen light-curing unit (Lunar, Benlioglu Dental, İstanbul, Turkeyl at an intensity of $620 \mathrm{~mW} / \mathrm{cm}^{2}$. The excess Resilon was removed from the coronal cavity up to the level of the cemento-enamel junction with a hot instrument.

Group 2: The MetaSEAL was hand-mixed on a mixing pad using one scoop of powder and three drops of liquid for 30 seconds and applied to the canal with a lentulo spiral filler. A size $45, .04$ tapered gutta-percha point (DiaDent Group Int., Canadal was coated with the sealer and introduced into the root canal. The excess material was removed from the coronal surface and light-cured for 40 s. Excess gutta-percha was removed from the coronal cavity up to the level of the cementoenamel junction with a hot instrument.

Group 3: The AH Plus (De Trey, Dentsply, Konstanz, DE) was applied to the root canal with a lentulo spiral filler. A size 45, .04 tapered guttapercha point was coated with $\mathrm{AH}$ Plus and intro- duced into the canals with tug-back. Excess material was removed, and the excess gutta-percha was removed with a hot instrument.

Obturated roots were kept in 100\% humidity conditions $\left(37^{\circ} \mathrm{C}\right)$ for one week. To examine the resin sealer-dentin interfaces, one root from each group was randomly selected for Scanning Electron Microscopy (SEM) analysis.

The apical $2 \mathrm{~mm}$ of the remaining roots $(n=10)$ were removed using a slow-speed, water-cooled diamond saw (Isomet, Buehler, Lake Bluff, IL). Each root was then sectioned at three levels (coronal, median and apical). The thickness of the sections was approximately $3 \pm 0.5 \mathrm{~mm}$. A total of 90 section surfaces were obtained. Digital images were taken from the apical side of each section in combination with a micrometer (Clemex, CL04-114-0607, Longueuil Canada), using a stereomicroscope (Olympus SZ40) at 10X magnification (Figure 1a, $b$ and $c$ ). The images were then transferred to a computer at the Photogrammetric Laboratory of the Faculty of Engineering (University of Selcuk, Konya, Turkeyl and evaluated for the surface area of all the gaps or voids. A total of three measurements were done for each root lcoronal apical and median). For this purpose, an affine transformation was done in the Netcad Software (Ak Mühendislik Ltd. Sti. Ankara, Turkey), and the surface area of the gaps or voids were calculated as $\mu \mathrm{m}^{2}$ (Figure 2). Scoring was done on a 0-3 scale according to accumulation of the gaps or voids. ' 0 '

Table 1. Ingredients, manufacturers and batch number of the sealers.

\begin{tabular}{|c|c|c|c|}
\hline Sealer & Ingredients & Manufacturer & Batch \\
\hline AH Plus & $\begin{array}{c}\text { Paste A: Bisphenol-A epoxy resin, } \\
\text { Bisphenol-F, epoxy resin, } \\
\text { Calcium tungstate, Zirconium oxide, Silica, } \\
\text { Iron oxide pigments. } \\
\text { Paste B: Dibenziyldiamine,Aminoadamantane, } \\
\text { Tricylodecane-diamine, } \\
\text { Calcium tungstate, Zirconium oxide, } \\
\text { Silica, Silicone oil. }\end{array}$ & $\begin{array}{l}\text { De Trey / Dentsply, } \\
\text { Konstanz, Germany }\end{array}$ & 0602002055 \\
\hline MetaSEAL & $\begin{array}{l}\text { Liquid: 4-META, monofunctionalmethacrylate } \\
\text { monomer, multifunctional } \\
\text { Macrylate monomers and photo-initiators; } \\
\text { Powder: Mixture of Zirconium oxide filler, SiO2 filler } \\
\text { and polymerization initiators. }\end{array}$ & Parkell Inc., NY & $\begin{array}{l}\text { Powder: } \\
060309 \\
\text { Liquid: } \\
051004\end{array}$ \\
\hline Epiphany & BisGMA, UDMA, hydrophilic methacrylates & $\begin{array}{c}\text { Pentron, Wallingford, CT, } \\
\text { USA }\end{array}$ & 103856 \\
\hline
\end{tabular}


represents no gaps or voids, ' 1 ' represents gaps or voids observed at one section and ' 3 ' represents gaps or voids observed at 3 sections lapical, median and coronal). The data was then statistically analyzed with a Kruskal-Wallis test.

The roots selected for SEM analysis were sectioned vertically into two pieces through the sealer, and each surface was then polished with 400 to 1200 grit silicon carbide abrasive papers. The interfaces were subjected to $10 \%$ phosphoric acid treatment for $3-5 \mathrm{~s}$, followed by $5 \%$ sodium hypochlorite immersion for 5 min. ${ }^{8}$ After being rinsed with distilled water, the samples were kept at room temperature for desiccation (24 h). Gold sputter coated interfaces were evaluated under SEM (JSM 5600, JEOL Ltd., Tokyo, Japan) operated at 20 kV.

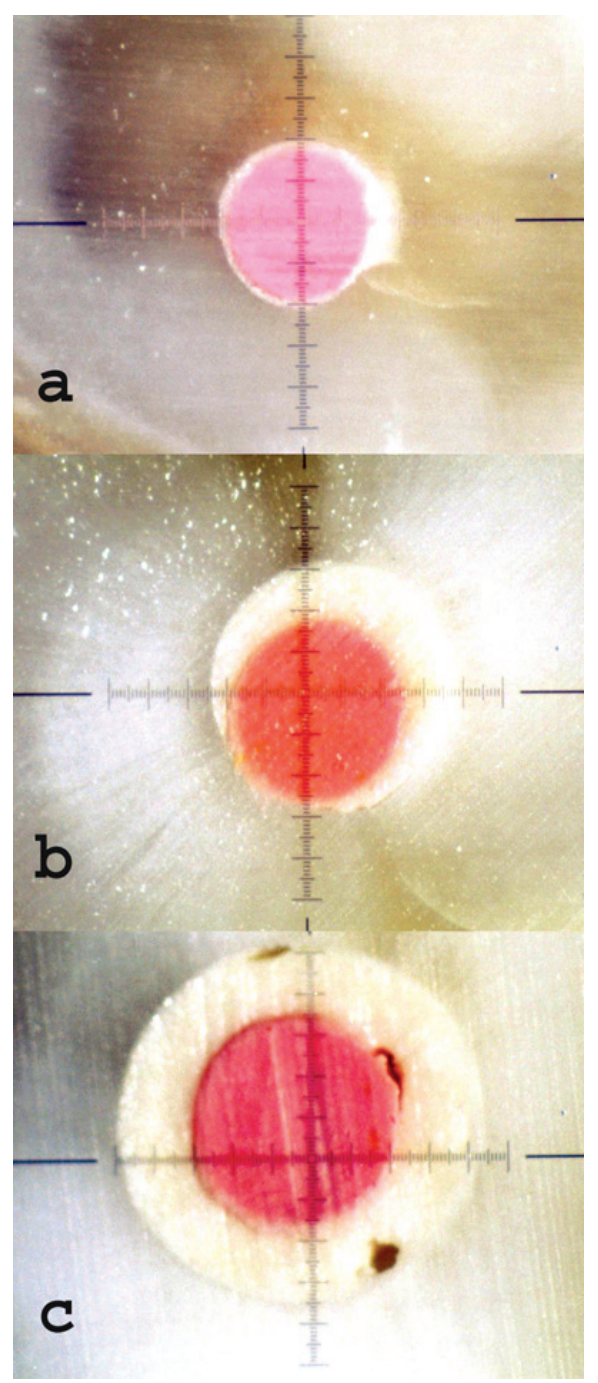

Figure 1. a. Microscopic image of the apical part of a sample. Digital images were taken in combination with a micrometer. b. Microscopic image of the median part of the same sample. c. Microscopic image of the median part of the same sample.

\section{RESULTS}

The measured surface areas of gaps or voids according to the materials and regions are shown in Table $2\left(\mu \mathrm{m}^{2}\right)$. When the scored data were analyzed, no significant differences were found among the sealers $(P=0.60)$. Table 2 shows the distribution of the percentage of the gap or voidfree sections by region and material. The AH Plus showed $100 \%$ gap or void-free interfaces at the apical region and the Epiphany showed $100 \%$ gap or void-free interfaces at the median. No significant differences were found among the sealers for the distribution of the gaps or voids by region (coronal, median or apical; P>.05).

When the interfaces of one sample from each group was observed under SEM, both the AH Plus and MetaSEAL samples showed an excellent adaptation to root dentin at the apical region (Fig-

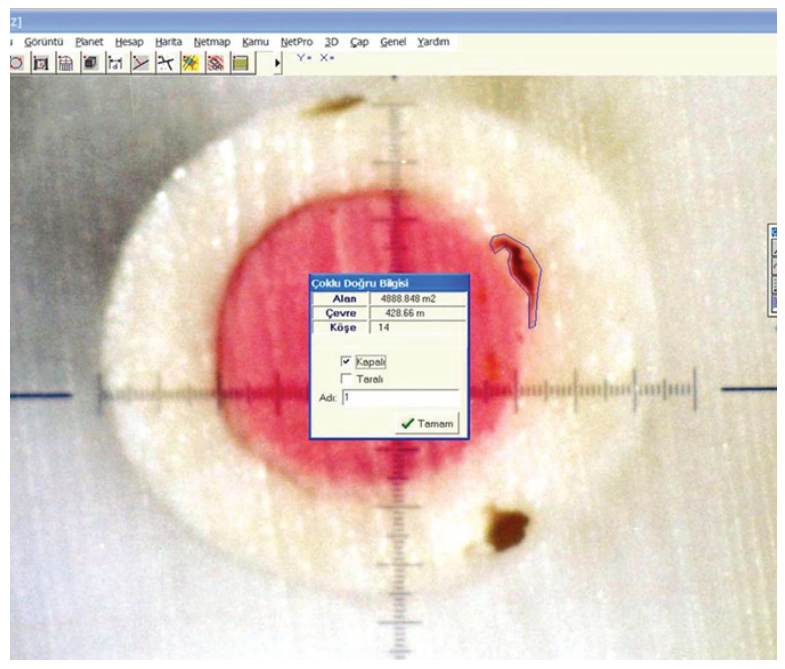

Figure 2. Affine transformation of the coronal part of a sample in the Netcad Software.

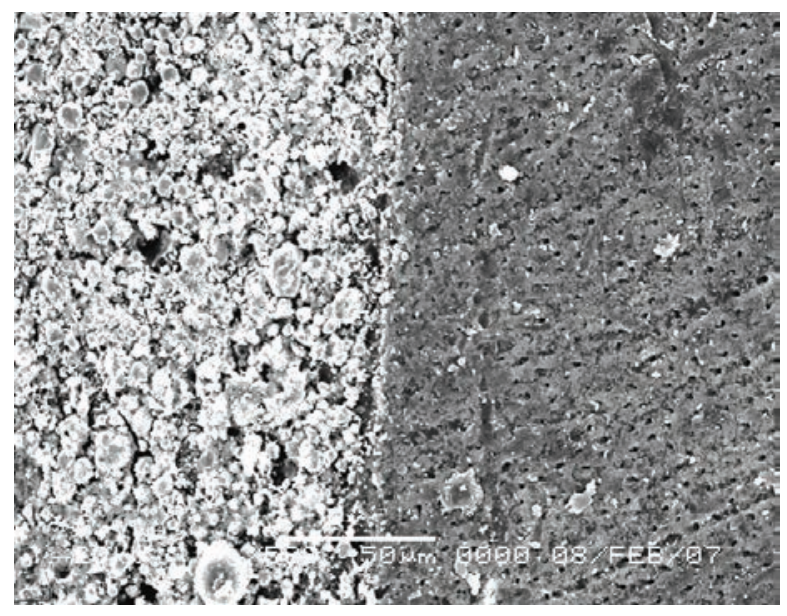

Figure 3. iSEM micrograph (500X) of a specimen that was filled with AH Plus and gutta-percha taken at a level of $2 \mathrm{~mm}$ from the apex. No void could be seen between the filled resin sealer and dentin. The sealer is closely adapted to the root dentine and gutta-percha. 
ures 3 and 4 ) and showed small voids within the sealer mass at the coronal region (Figures 5 and 6). The Epiphany sample showed gap formation at the apical region (Figure 7), and the sealer was closely adapted to the root dentin surfaces at the coronal region (Figure 8).

\section{DISCUSSION}

An aim of obturation is to have the maximum amount of gutta-percha filling. Wesselink reported that the amount of sealer should be minimized, and the solid nucleus of gutta-percha should be maximized for better sealing. ${ }^{29}$ The lateral condensation technique, as classically described, involves the use of an ISO-standardized $0.2 \mathrm{~mm} / \mathrm{mm}$ tapered master gutta-percha cone. However, lateral condensation, unlike vertical condensation, does not create a homogenous mass of gutta-

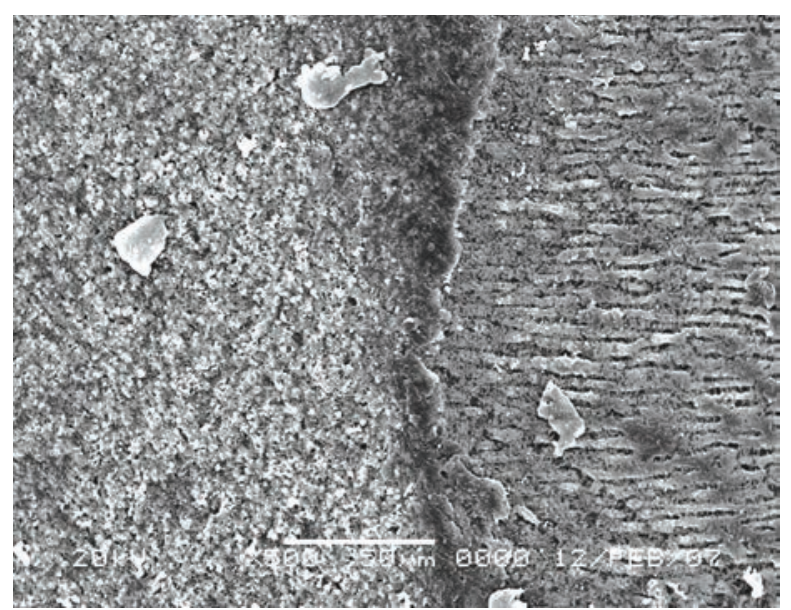

Figure 4. SEM micrograph (500X) of longitudinal section of a root filled with MetaSEAL and gutta-percha taken at a level of $2 \mathrm{~mm}$ from the apex. No void could be discerned between the sealer and the root dentin, and no resin tags could be identified

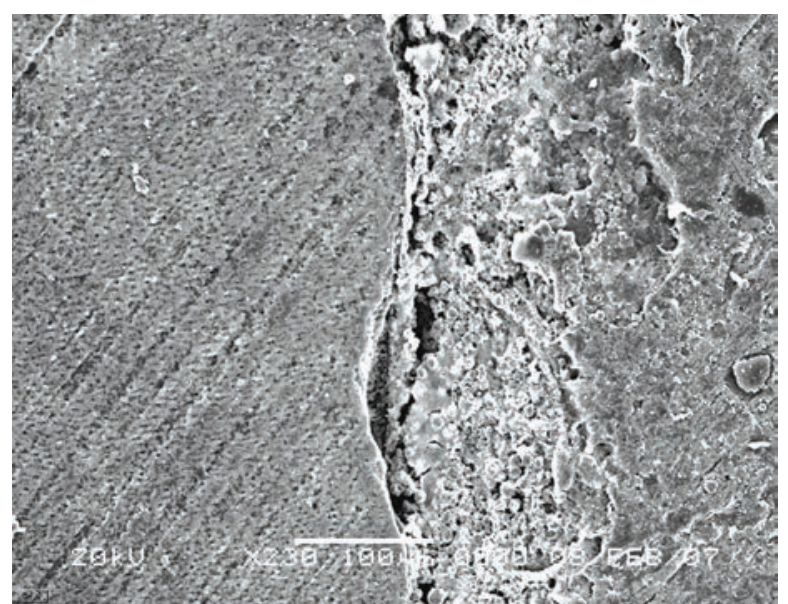

Figure 5. SEM micrograph (230X) of longitudinal section of the same specimen filled with $\mathrm{AH}$ Plus and gutta-percha at a level of $3 \mathrm{~mm}$ from the coronal. A void is evident between the sealer and root dentin. No resin tags could be identified in dentinal tubules. percha. Therefore, filling with a master cone with a larger taper may be advantageous because a larger and more uniform mass of gutta-percha is introduced into the root canal. ${ }^{30}$ Gordon et al indicated that the single cone results were not significantly different from the lateral condensation results, indicating that the method was comparable with lateral condensation. ${ }^{25}$ Obturating straight root canals in vitro with laterally condensed .06 tapered gutta-percha master cones that match the shape of .06 tapered nickel-titanium rotary instruments prevent complete bacterial penetration as effectively as laterally condensed .02 tapered master cones. ${ }^{30}$ If a round shape is made in the canal preparation, a well-fit single cone with sealer can be used for adequate obturation, and there have been multiple studies in which a single cone method of obturation was successfully used. ${ }^{25,31-33}$ In the present study, root canals were instrumented with ProFile .04 tapered NiTi rotary instruments to improve preparation of a uniformly round space. MetaSEAL is recommended for use exclusively with cold compaction or single-cone techniques; $i^{14}$ therefore, the single cone technique was used during the obturation of the canals using a .04 tapered gutta-percha or Resilon. Although the match-taper single-cone technique was used, the sealer thickness was increased from the apical to coronal regions in all samples. The thinnest sealer was observed at the apical region and the thickest sealer was observed at coronal region (Figure 1a, b and c). When the distribution of the gaps or voids was evaluated, only the $\mathrm{AH}$ Plus group showed $100 \%$ gap or void-free interfaces at

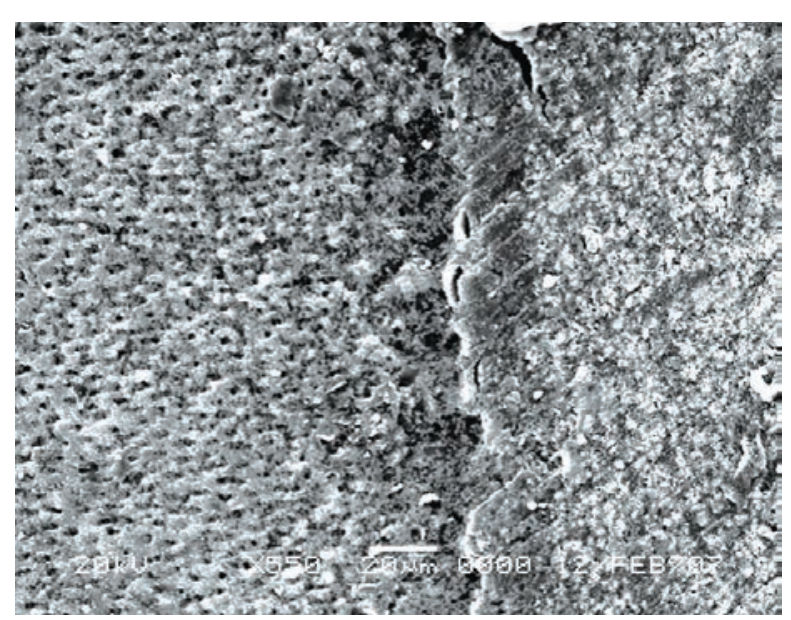

Figure 6. SEM micrograph (550X) of coronal region of the same specimen taken at a level of $3 \mathrm{~mm}$ from the coronal side. The root was filled with MetaSEAL and gutta-percha. Small voids were identified between the sealer and root dentin. No resin tags could be identified.

\section{April 2010 - Vol.4}


the apical region. This result shows that maximizing the solid nucleus of gutta-percha and minimizing the amount of sealer is an effective method to prevent gap or void formation, at least for AH Plus.

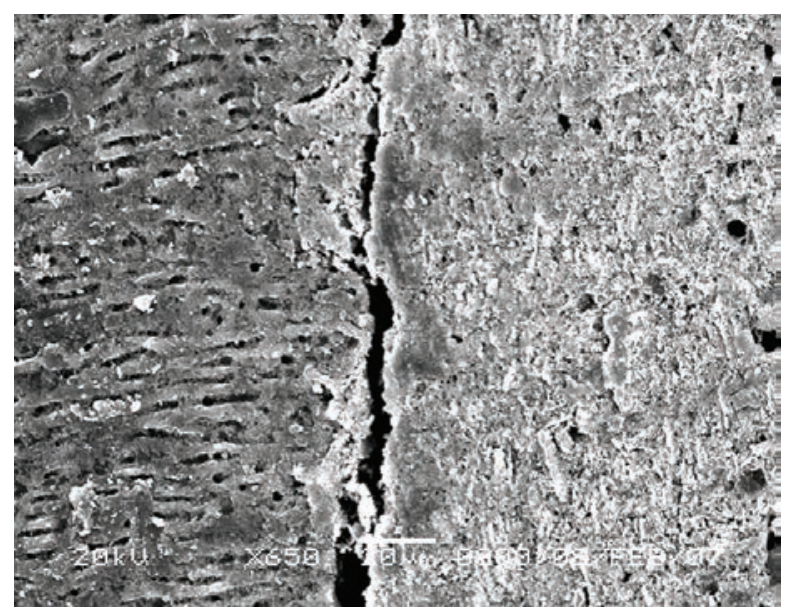

Figure 7. SEM micrograph (650X) of apical region of a root filled with Epiphany and Resilon taken at a level of $2 \mathrm{~mm}$ from the apex. A void could be seen between the sealer and Resilon. The sealer is very thin, and the resin penetration into the dentinal tubules cannot be identified.
On the other hand, decreasing the sealer thickness with Resilon or gutta-percha could not prevent gap or void formation in the MetaSEAL (10\%) and Epiphany groups (20\%) (Table 2, Figure 7).

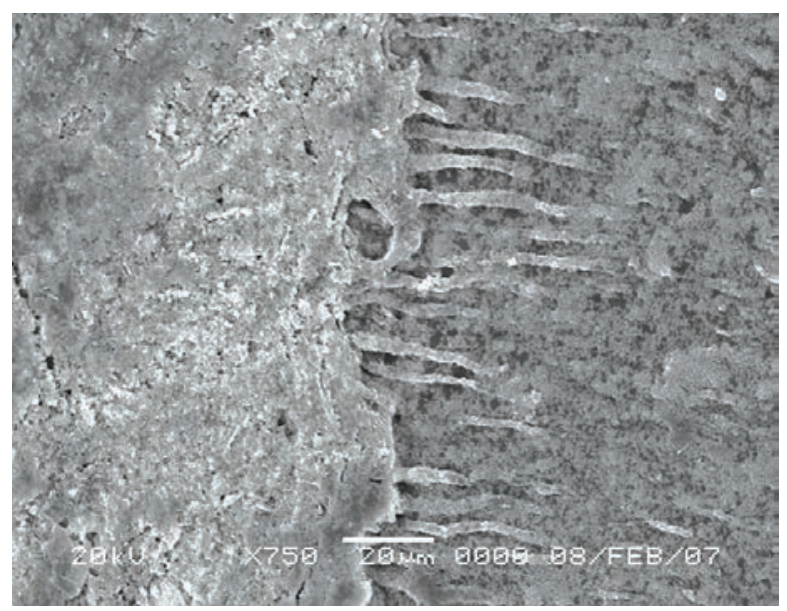

Figure 8. SEM micrograph (750X) of coronal region of the same specimen root filled with Epiphany and Resilon. The sealer is closely adapted to the root dentine, and numerous resin tags extended into the dentin tubules.

Table 2. Total area of the gaps or voids $\left(\mu \mathrm{m}^{2}\right)$ and percentage of gap- or void-free interfaces according to the regions.

\begin{tabular}{|c|c|c|c|c|c|c|c|c|c|}
\hline & \multicolumn{3}{|c|}{ AH Plus / Gutta-percha } & \multicolumn{3}{|c|}{ MetaSEAL / Gutta-percha } & \multicolumn{3}{|c|}{ Epiphany / Resilon } \\
\hline & Apical & Median & Coronal & Apical & Median & Coronal & Apical & Median & Coronal \\
\hline$\%$ & 100 & 80 & 50 & 80 & 80 & 90 & 80 & 100 & 70 \\
\hline 1 & 0 & 0 & 0 & 0 & 0 & 0 & 0 & 0 & 0 \\
\hline 2 & 0 & 0 & 0 & 0 & 0 & 0 & 0 & 0 & 0 \\
\hline 3 & 0 & 0 & 0 & 0 & 0 & 0 & 0 & 0 & 0 \\
\hline 4 & 0 & 0 & 0 & $\begin{array}{l}580^{\mathrm{s}} \\
432^{\mathrm{g}}\end{array}$ & $2174^{s}$ & 0 & $1183^{9}$ & 0 & 0 \\
\hline 5 & 0 & $\begin{array}{c}10844^{9} \\
5515^{\mathrm{s}}\end{array}$ & $\begin{array}{l}349632^{\mathrm{s}} \\
313870^{\mathrm{d}}\end{array}$ & 0 & 0 & $\begin{array}{c}16209^{d} \\
553^{s}\end{array}$ & 0 & 0 & $6061^{d}$ \\
\hline 6 & 0 & 0 & $\begin{array}{c}118226^{5} \\
25603^{9}\end{array}$ & 0 & 0 & 0 & 0 & 0 & $14685^{r}$ \\
\hline 7 & 0 & 0 & 0 & 0 & 0 & 0 & $12008^{d}$ & 0 & 0 \\
\hline 8 & 0 & 0 & $6302^{s}$ & 0 & $18320^{5}$ & 0 & 0 & 0 & 0 \\
\hline 9 & 0 & 0 & $7241^{\mathrm{s}}$ & 0 & 0 & 0 & 0 & 0 & $12381^{r}$ \\
\hline 10 & 0 & $338450^{s}$ & $461112^{s}$ & 0 & 0 & 0 & 0 & 0 & 0 \\
\hline
\end{tabular}

g: Gaps between gutta-percha or Resilon and sealant; s: Voids inside the sealant; $d$ : Gaps between the sealant and root dentin; r: Gaps between Resilon and sealant. 
Structural deficiencies are generally originated from the air trapped in the sealer mass during mixing or transferring of the sealer. ${ }^{22}$ Mutal et al indicated that the presence of structural deficiencies also depend on the physical properties of the sealer, such as density or flow. ${ }^{22}$ Unlike Epiphany and AH Plus, the MetaSEAL consists of powder and liquid. The material has a long working time $(30 \mathrm{~min})$ and an 8 min curing time (unpublished data by Parkell). All the samples were light-cured from the coronal region for $40 \mathrm{~s}$ as in Epiphany Group. The results indicated that 20\% of samples showed void formation at the median, and $90 \%$ of the samples were gap or void-free at both the apical and coronal regions. The Epiphany group showed $100 \%$ gap or void-free interfaces at the median (Table 4). No significant differences were found between the Epiphany and MetaSEAL groups $(P=0.60)$.

The amount of resin flow that occurs during polymerization is determined by the configuration of the cavity, and the cavity configuration factor (C-factor) is defined as the ratio of the bonded to the unbonded surface area. ${ }^{34}$ Resin-based sealers are bonded 360 degrees around the periphery of the canal, and only the surface area at the top of the canal orifice allows flow of the sealer during shrinkage. A root canal could create $\mathrm{C}$-factors of 20 to 100 depending on the diameter and length of the canal. ${ }^{35}$ Tay et al indicated that in root canals, C-factors can be over 1000. Large polymerization stresses during setting may lead to debonding of the resin from the canal wall or may cause void formation along the periphery of the root filling. ${ }^{36}$ Stress relief by resin flow partially depends upon resin film thickness. ${ }^{37,38}$ However, in a root canal, stress relief by flow is not sufficient because the unbonded surface area becomes smaller, and the forces of polymerization shrinkage can exceed the resin bond strength to root dentine, permitting debonding on one side of the filling to relieve stress. ${ }^{36}$ In this study, AH Plus showed $50 \%$, Epiphany $50 \%$ and MetaSEAL showed $70 \%$ gap-free interfaces from the apical to coronal regions (Table 2). On the other hand, when the samples with gaps were evaluated, it was observed that when the apical region was $100 \%$ gap-free, there was a gap at the coronal (AH Plus) or median regions, and when the median was $100 \%$ gap-free, then there were gaps or voids at both the apical and coronal regions (Epiphany). These results confirm the idea that the $\mathrm{C}$-factor affects the performance of the resin-based sealers, and as a result of the shrinkage stresses, debonded areas can occur.

To overcome shrinkage stresses, the materials should have a strong adhesion. In the present study, MetaSEAL and Epiphany showed more $100 \%$ gap-free interfaces than AH Plus (not sig.). Their adhesion ability seemed to be high enough to overcome shrinkage stresses. A slow polymerizing sealer can help relieve the shrinkage stress via resin flow. MetaSEAL polymerizes in room temperature in 30 minutes. Light-curing to create an immediate coronal seal may prevent flow of resin sealer. ${ }^{39}$ In the present study, both Epiphany and MetaSEAL groups were light cured from the coronal region according to the manufacturers' instructions. The results might be different if these sealers were set without additional light curing.

Obturation quality is generally determined by evaluating the amount of apical or coronal leakage in root-filled teeth. Wu et al reported that the thickness of the sealer layer is a factor that can affect the sealing ability. ${ }^{40}$ In a microbial leakage study, Shipper et al found Resilon groups superior to gutta-percha groups. ${ }^{5}$

Examination of fully hydrated specimens by environmental scanning electron microscope (ESEM) is essential for differentiating genuine voids between root filling and dentin that are susceptible to leakage of microorganisms and antigens, from potential artifactual voids created after vacuum desiccation in conventional SEM's. ${ }^{6,41}$ In the present study, the evaluation of the voids was done on digital images taken from hydrated samples under stereomicroscope. A sample from each group was evaluated using conventional SEM. Kataoka et al evaluated the sealing ability of a resin-based root canal sealer and conducted tensile bond strength measurements, the dye penetration test and SEM observation. ${ }^{42}$ The results indicated that the dye penetration test results were supported by the conventional SEM observations. In the present study, when the SEM images were evaluated, the results were similar to the digital image evaluation results, although ESEM was not used.

In this study, the 'Affine Transformation Method' was used to calculate the area of the gaps or voids. Although the Affine Transformation Method 
is generally used in engineering and photogrammetric fields, in this paper, we introduced this technique for the quantitative analyses of microscopic images of sectioned roots. Three sections were obtained from each root. A micrometer and a stereomicroscope were used to obtain images, and the Netcad Software was used for the Affine Transformation. The operator who defined the voids for analysis using the Netcad Software was blinded the assigned sealer of each sample. The same parameters were used for all samples. This method appears to be a practical method for calculating surface areas from digital photographs. Other methods for the evaluation of root fillings include histological sectioning and subsequent evaluation of voids by image analysis, ${ }^{32,43}$ radiographic techniques, ${ }^{44}$ the density evaluation using weighing ${ }^{45}$ or measuring the amount of spreader penetration $^{30}$ or the micro-CT technique. ${ }^{27}$ The technique used in this study was easy to use and allowed detailed evaluation of the voids verified with the microscope or with digital images of high resolution. One of the limitations of this study was the destruction of the samples and structural loss during cutting with the diamond saws given the thickness of the saw. Three sections from one root representing three different regions lapical, median and coronal) were evaluated in this study. This technique did not allow for three dimensional evaluation of the gaps or voids, but it can be improved by increasing the number of the sections. Future studies are needed to improve the use of this technique in the dental field.

\section{CONCLUSIONS}

Within the limitations of this study, the following results can be drawn:

- The recently developed 4-META containing sealer, MetaSEAL, showed similar interfaces with the sealer Epiphany.

- When the mean surface area of the voids was scored on a 0-3 scale, no significant differences were found among the groups.

- The 'Affine Transformation Method' allowed evaluation of the gaps or voids on the digital images of root filled teeth.

\section{REFERENCES}

1. Byström A, Sundqvist G. Bacteriological evaluation of the effect of 0.5 percent sodium hypochlorite in endodontic therapy. Oral Surg Oral Med Oral Pathol 1983;55:307-312.
2. Imai Y, Komayabayashi T. Properties of a new enjectable type of root canal filling resin with adhesiveness to dentin. J Endod 2003;29:20-23.

3. Bouillaguet S, Troesch S, Wataha JC, Krejci I, Meyer JM, Pashley DH. Microtensile bond strength between adhesive cements and root canal dentin. Dent Mater 2003;19:199205.

4. Lombardo GHL, Souza ROA, Michida SMA, Melo RM, Bottino MA, Valandro RF. Resin bonding to root canal dentin: Effect of the application of an experimental hydrophobic resin coating after an all-in-one adhesive. J Contemp Dent Pract 2008;9:1-10.

5. Shipper G, Orstavik D, Teixeira FB, Trope M. An evaluation of microbial leakage in roots filled with a thermoplastic synthetic polymer based root canal filling material (Resilon). J Endod 2004;30:342-347.

6. Stratton RK, Apicella MJ, Mines P. A fluid filtration comparison of gutta-percha versus Resilon, a new soft resin endodontic obturation system. J Endod 2006;32:642-645.

7. Teixeira FB, Teixeira EC, Thompson JY, Trope M. Fracture resistance of roots endodontically treated with a new resin filling material. J Am Dent Assoc 2004;135: 646-652.

8. Tay FR, Loushine RJ, Weller RN, Kimbrough WF, Pashley DH, Mak YF, Lai CNS, Raina R, Williams MC. Ultrastructural evaluation of the apical seal in roots filled with a polycaprolactone-based root canal filling material. J Endod 2005;31:514-519.

9. Gordan W, Vargas MA, Cobb DS, Denehy GE. Evaluation of adhesive systems using acidic primers. Am J Dent 1997;10:219.

10. Britto LR, Borer RE, Vertucci FJ, Haddix JE, Gordan VV. Comparison of the apical seal obtained by a dual cure resin based cement or an epoxy resin sealer with or without the use of an acidic primer. J Endod 2002;28:721-723.

11. Nakabayashi N, Kojima K, Masuhara E. The promotion of adhesion by the infiltration of monomers into tooth substrates. J Biomed Mater Res 1982;16:265-273.

12. Nakabayashi N, Pashley DH. Hybridization of dental hard tissues. Quintessence Publishing Co., Ltd, Tokyo, Japan. 1998; p:11.

13. Nakabayashi N, Takarada K. Effect of HEMA on bonding to dentin. Dent Mater 1992;8:125-130.

14. Lawson MS, Loushine B, Mai S, Weller RN, Pashley DH, Tay FR, Loushine RJ. Resistance of a 4-META-containing, methacrylate-based sealer to dislocation in root canals. $J$ Endod 2008;34: 833-837.

15. Tay FR, Pashley DH, Williams MC, Raine R, Loushine RJ, Weller RN, Kimbrough WF, King NM. Suspectibility of a polycaprolactone-based root canal filling material to degradation. 1. Alkaline hydrolysis. J Endod 2005;31:593-598.

16. Key JE, Rahemtulla FG, Eleazer PD. Cytotoxicity of a new root canal filling material on human gingival fibroblasts. $J$ Endod 2006;32:756-758 
17. Tay FR, Hiraishi N, Pashley DH, Loushine RJ, Weller N, Gillespie WT, Doyle MD. Bondability of resilon to a methacrylate-based root canal sealer. J Endod 2006;32:133-137.

18. Hiraishi N, Papachini F, Loushine RJ, Weller RN, Ferrari M, Pashley DH, Tay FR. Shear bond strength of Resion to a methacrylate-based root canal sealer. Int Endod $J$ 2005;38:753-763

19. Biggs SG, Knowles KI, Ibarrola JL, Pashley DH. An in vitro assessment of the sealing ability of resilon/epiphany using fluid filtration. $J$ Endod 2006;32:759-761.

20. Maltezos C, Glickman GN, Ezzo P, He J. Comparison of the sealing of Resilon, Pro Root MTA and Super EBA as root end filling materials: A bacterial leakage study. J Endod 2006;32:324-327

21. Sousa CJA, Montes CRM, Pascon EA, Loyola AM, Versiani MA. Comparison of the intraosseous biocompatibility of $\mathrm{AH}$ Plus, EndoREZ and Epiphany root canal sealers. J Endod 2006;32:656-662.

22. Mutal L, Gani O. Presence of pores and vacuoles in set endodontic sealers. Int Endod J 2005;38:690-696.

23. Wu MK, de Groot SD, van der Sluis LW, Wesselink PR. The effect of using an inverted master cone in lateral compaction technique on the density of the gutta-percha fill. Oral Surg Oral Med Oral Pathol Oral Radiol Endod 2003;96:345350.

24. ElAyouti A, Achleithner C, Löst C, Weiger R. Homogenity and adaptation of a new gutta-percha paste to root canal walls. J Endod 2005;31:68-90.

25. Gordon MPJ, Love RM, Chandler NP. An evaluation of .06 tapered gutta-percha cones for filling of .06 taper prepared curved root canals. Int Endod J 2005;38:87-96.

26. Epley S, Fleischman J, Hartwell G, Cicalese C. Completeness of root canal obturations: Epiphany techniques versus gutta-percha techniques. J Endod 2006;32:541-544.

27. Jung M, Lommel D, Klimek J. The imaging of root canal obturation using micro-CT. Int Endod J 2005;38:617-626.

28. Karl Kraus Photogrammetry, WB-Druck, Vol:1, ISBN 3-427-78684-6, 397:186 1993.

29. Wesselink PR. Conventional root-canal therapy III. Root filling. In: Harty FJ. Ed. Endodontics in Clinical Practice, 3'rd Ed. London,UK:, Butterworth, 186-223 1990.

30. Bal AS, Hicks ML, Barnett F. Comparison of laterally condensed .06 and .02 tapered gutta-percha and sealer in vitro. J Endod 2001;27:786-8.

31. Deutsch P, Musikant P. A study of one visit treatment using EZ-Fill root canal sealer. Endod Pract 2001;1:29-36.

32. Hembrough MW, Steiman HR, Belanger KK. Lateral condensation in canals prepared with nickel titanium rotary instruments: an evaluation of the use of three different master cones. J Endod 2002;28:516-519.
33. Kardon BP, Kuttler S, Hardigan P, Dorn SO An in vitro evaluation of the sealing ability of a new root-canal-obturation system. J Endod 2003;29:658-661.

34. Davidson CL, de Gee AJ, Feilzer AJ. The competition between the composite-dentin bond strength and the polymerization contraction stress. J Dent Res 1984;63:1396-1399.

35. Morris MD, Lee KW, Agee KA, Bouillaguet S, Pashley $\mathrm{DH}$. Effects of sodium hypochlorite and RC-Prep on bond strengths of resin cement to endodontic surfaces. J Endod 2001;27:12:753-757.

36. Tay FR, Loushine RJ, Lambrechts P, Weller RN, Pashley DH Geometric factors affecting dentin bonding in root canals: a theoretical modeling approach. J Endod 2005;31:584589.

37. Feilzer AJ, de Gee AJ, Davidson CL. Increased wall-to-wall curing contraction in thin bonded resin layers. $J$ Dent Res 1989;68:48-50.

38. Alster D, Feilzer AJ, de Gee AJ, Davidson CL. Polymerization contraction stress in thin composite layers as a function of layer thickness. Dent Mater 1997;13:146-150.

39. Braga RR, Ferracane JL, Condon JR. Polymerization contraction stress in dual-cure cements and its effect on interfacial integrity of bonded inlays. J Dent 2002;30:333340.

40. Wu MK, Wesselink PR, Boersma J. A 1-year follow-up study on leakage of four root canal sealers at different thickness. Int Endod J 1995;28:185-189.

41. Tay FR, Sidhu SK, Watson TF, Pashley DH. Water dependent interfacial transition zone in resin-modified glassionomer cement/dentin interfaces. J Dent Res 2004,83:644649.

42. Kataoka H, Yoshioka T, Suda H, Imai Y. Dentin bonding and sealing ability of a new root canal resin sealer. $J$ Endod 2000;26:230-235.

43. Wu MK, Wesselink PR. A primary observation on the preparation and obturation of oval canals. Int Endod $J$ 2001;26:137-141.

44. Goldberg F, Artaza LP, De Silvio A. Effectiveness of different obturation techniques in the filling of simulated lateral canals. J Endod 2001;27:362-364.

45. Deitch AK, Leiwehr FR, West LA, Patton WR. A comparison of filled density obtained by supplementing cold lateral condensation with ultrasonic condensation. J Endod 2002;28:665-667. 